\title{
Una mirada patagónica sobre la integración. El caso del diario Río Negro y las relaciones argentino-chilenas $(1960-1973)^{*}$
}

\author{
A Patagonian look on integration. The case of the diary RÍO NEGRO and the \\ argentine-chilean relations (1960-1973)
}

\author{
Alfredo Azcoitia* \\ Instituto de Investigaciones en Diversidad Cultural y Procesos del Cambio, \\ Universidad Nacional de Río Negro
}

Recibido: 17.04.2017. Aprobado: 29.08.2017

\begin{abstract}
Resumen
En el presente artículo proponemos analizar los distintos sentidos que adquirieron los discursos sobre la integración argentino-chilena que circularon en la prensa norpatagónica, desde la conformación del ALALC hasta el final de la autodenominada "Revolución Argentina". Para ello, recurrimos al diario más influyente de una región cuya territorialización estuvo atravesada por una multiplicidad de procesos que se vinculan tempranamente a Chile. En este sentido, podemos mencionar la continua circulación de trabajadores, mercancías y capitales, de uno y al otro lado de la cordillera, que no solo ha tenido importancia económica, sino que también configuró un sustancial aporte social y cultural para la región. Sin embargo, este estrecho vínculo también ha despertado históricos temores del nacionalismo territorial, que dieron vida a las más variadas teorías conspirativas. En suma, la tensión entre la profundización de los vínculos transcordilleranos y los temores al "vecino expansionista", constitutiva del espacio patagónico, junto a las características propias de un período signado por la creciente pretorización de la sociedad y del Estado argentino, configuran un escenario por demás
\end{abstract}

Este trabajo se enmarca en el PICT-2014-0992 "Miradas binacionales sobre Patagonia Norte: Desarrollo territorial, cultura e identidades sociales en el siglo XX”, dirigido por la Dra. María Andrea Nicoletti.

** Doctor en Historia, Instituto de Investigaciones en Diversidad Cultural y Procesos del Cambio, Universidad Nacional de Río Negro, La Florida 3603, San Carlos de Bariloche, Provincia de Río Negro, Argentina. alfazkoitia@ hotmail.com. 
propicio para indagar sobre la polisemia desplegada durante esos años por los discursos integracionistas.

Palabras clave: integración, prensa, Patagonia.

\begin{abstract}
In the present article we propose an analysis of the different senses that acquired the discourses on the Argentine-Chilean integration that circulated in the norpatagonian press, from the conformation of the ALALC until the end of the self-named "Argentine Revolution". To do this we resort to the most influential newspaper in a region whose territory was crossed by a multiplicity of processes that are linked early to Chile. In this sense we can mention the continuous movement of workers, goods and capital, from one side of the Andes mountain range, which has not only economic importance, but also shaped a substantial social and cultural contribution to the region. However, this close link has also awakened historical fears of territorial nationalism, which gave life to the most varied conspiracy theories. In summary, the tension between the deepening of ties across the Andes and the fears of the "expansionist neighbor," made up of the Patagonian space, together with the characteristics of a period marked by growing insecurity of society and the Argentine State, constitutes a scenario which was also conducive to the study of the polysemy deployed during those years by integrationist discourses.
\end{abstract}

Keywords: integration, press, Patagonia.

\title{
Introducción
}

Desde su conformación como repúblicas independientes, la relación entre Chile y la Argentina estuvo signada por la alternancia entre momentos en los que las tensiones fronterizas parecieron constituir una seria amenaza para la paz Regional ${ }^{1}$, seguidos por otros en los cuales prevalecieron políticas y discursos tendientes a profundizar la cooperación

1 En el transcurso del artículo usaremos el término región para referirnos tanto a la unidad supranacional América Latina como a la subnacional Norpatagonia. En el primer caso emplearemos la mayúscula reservando el uso de la minúscula para referir al segundo. 
binacional. En este sentido, los debates que a mediados del siglo XX se sucedieron en América Latina en torno a la modernización, el desarrollo, la industrialización, el rol de las clases sociales y la relación centro-periferia, fueron conformando un contexto propicio para aquellos actores y discursos que bregaban por una mayor integración entre ambos países (Nercesian, 2013). Asimismo, el estallido de la Revolución Cubana a fines de la década del cincuenta, el lanzamiento de la Alianza para el Progreso a principio de los sesenta, el proceso de pretorización de la vida política argentina que sobrevino luego del derrocamiento de Juan Domingo Perón (1946-1955), junto con los profundos cambios políticos y sociales producidos en Chile, fueron configurando diversos escenarios que resignificaron los discursos integracionistas que circularon por la Argentina durante esos años.

En la Patagonia, esta situación adquirió un carácter particular al ser una región cuya territorialización estuvo atravesada por una multiplicidad de procesos que se vinculan a Chile en forma tan profunda como temprana. Entre ellos cabe destacar el denso entramado de relaciones económicas, sociales y culturales que fue gestándose desde el siglo XIX a través de los intercambios comerciales y de los continuos desplazamientos de trabajadores a uno y otro lado de la cordillera. Sin embargo, esta nutrida presencia de migrantes también despertó los históricos temores del nacionalismo territorial que alimentaron permanentes hipótesis de conflicto y dieron lugar a las más diversas teorías conspirativas (Bohoslavsky, 2009). En este sentido, consideramos que la tensión entre la profundización de los vínculos transcordilleranos y la desconfianza al "vecino expansionista" ${ }^{2}$, la cual constituye un rasgo característico de la región patagónica, le imprime una mayor densidad semántica al discurso sobre la integración binacional al circular por un espacio donde "Chile" no resulta una referencia lejana y abstracta sino que, por el contrario, constituye una experiencia tan concreta como cotidiana.

En función de lo expuesto hasta aquí, en el presente artículo nos proponemos analizar la multiplicidad de sentidos sobre la integración argentino-chilena que fueron desplegándose en las páginas del diario patagónico Río Negro, desde la firma de los acuerdos que dieron origen a la Asociación de Libre Comercio (1960) hasta la asunción del presidente argentino Héctor J. Cámpora (1973). Este período resulta por demás significativo para nuestro

2 Para Paulo Cavaleri (2004), el nacionalismo territorial concebía al Virreinato del Río de la Plata como molde natural de la argentinidad. Desde esta perspectiva, los países vecinos eran sindicados como responsables de un despojo imaginario que privó a la Argentina de su destino de grandeza. En este sentido, Pablo Lacoste (2003) ha realizado una exhaustiva pesquisa sobre la cartografía y la documentación colonial, revelando las imprecisiones sobre las que se construyó la representación nacionalista de la "Argentina bioceánica", como también la influencia que ejerció a lo largo de los siglos XIX y XX. 
análisis, no solo por la fuerza que alcanzó la integración regional en tanto significante, sino también por los distintos significados que fue adquiriendo, en un contexto atravesado por la tensión creciente entre los antagonismos: dictadura y democracia, revolución y conservadurismo, radicalidad y reformismo, entre otros. Establecemos como cierre el año 1973 por considerar que a partir de ese momento, con el avance de la derecha en la Argentina y el golpe de Estado en Chile, comienza a configurarse un nuevo escenario, en el que dichas tensiones encuentran una resolución en favor de la opción reaccionaria.

Sobre la elección del Río Negro, resulta pertinente aclarar que a través de este medio no pretendemos condensar los discursos de la prensa patagónica, los cuales son tan numerosos como variados, sino centrar nuestro análisis en un diario cuya influencia sobre la opinión pública regional, principalmente norpatagónica, ha sido indiscutible a lo largo de todo el siglo XX. Fundado por Fernando Emilio Rajneri el $1^{\circ}$ de mayo de 1912, este periódico publicado en la ciudad rionegrina de General Roca evidenció tempranamente su pretensión de erigirse en un actor político ${ }^{3}$ regional con capacidad de mediar entre los habitantes y los poderes políticos territorianos ${ }^{4}$, vehiculizando las demandas de los primeros y ejerciendo un permanente control sobre los últimos (Ruffini, 2001). En 1958 comenzó a publicarse en forma diaria, alcanzando el liderazgo regional en el transcurso de la década del sesenta, para convertirse en los años setenta y ochenta en uno de los medios de prensa más importantes del país. Esto fue posible tanto por los importantes vínculos políticos forjados por la familia fundadora y, hasta hoy en día, propietaria del diario, como por las continuas inversiones en equipamiento y la permanente actualización de su diagramación, lo que le han permitido mantener su vigencia a lo largo del cambiante siglo XX. De esta forma, consideramos que recorrer los distintos sentidos que adquirió la integración a través del Río Negro permite develar tanto la posición asumida por un actor político central de la norpatagonia argentina, como también identificar aquellos discursos que ejercieron mayor influencia en una región cuya territorialización estuvo permanentemente atravesada por la tensión entre el conflicto y la cooperación con Chile.

Héctor Borrat (1989) define al periódico independiente de información general como un actor político de naturaleza colectiva, cuyo ámbito de actuación es el de la influencia pública y no el de la conquista del poder institucional.

4 Este término refiere a los Territorios Nacionales, que fue la forma jurídico-administrativa que adoptaron a partir de la sanción de la Ley 1.532 de 1884 las tierras arrebatadas a los pueblos originarios por parte del Estado argentino. Bajo esta ley, los habitantes territorianos quedaron en situación de inferioridad debido a la "inmadurez" cívica que les impedía actuar en forma autónoma al "carecer", en razón de residir en espacios que estuvieron bajo dominio indígena, de "civilización y cultura cívica”. En este marco institucional, la sociedad local se constituyó como actor político haciendo escuchar su voz a través de la participación en las asociaciones y en la prensa territoriana (Ruffini, 2007). 
Antes de comenzar con nuestro análisis, resulta indispensable realizar algunas precisiones de orden teórico y metodológico. El artículo propone abordar la superficie redaccional del diario apelando a herramientas conceptuales del análisis del discurso. Esta decisión implica que lejos de concebirse al discurso como un medio transparente por el cual se accede a una "realidad" externa a él, se asume como una forma de construir, mantener y reforzar interpretaciones sobre la misma, a través de la producción de representaciones de la sociedad, de sus actores, relaciones y prácticas (Fairclough, 1992; Martín Rojo, 1997). Desde el punto de vista metodológico, analizamos las distintas unidades comunicativas que componían el diario, teniendo en cuenta tanto variables relativas a sus aspectos formales (titulares, ilustración, etc.) como a su contenido. El análisis no se limitó a ninguna sección en particular, ya que el objetivo no era ceñirse solo a la línea editorial de Río Negro, sino también dar cuenta de otros discursos que habitaron su superficie redaccional. El corpus documental del artículo se integra por las noticias, editoriales y notas de opinión que tuvieron como tema central los vínculos binacionales.

\section{La creación del ALALC y la integración como potencialidad}

En el marco de los debates en torno a la modernización y el desarrollo latinoamericanos, suscitados a mediados del siglo XX, fue cobrando fuerza en la Región la idea de que se estaban gestando condiciones para impulsar políticas tendientes a profundizar el proceso de industrialización. Distintas voces que se inscribían en el influyente paradigma desarrollista ${ }^{5}$ sostenían que las potencias hegemónicas disminuirían sus gastos militares, generando así un flujo de capitales que se destinarían al desarrollo económico de las periferias. Desde esta perspectiva, como consecuencia de la etapa de distensión en la que había ingresado la Guerra Fría, solo interrumpida por la crisis de 1962 en torno a los misiles soviéticos en Cuba, la disputa entre los EE.UU. y la URSS se desplazaría del campo militar al económico (Hobsbawm, 1995).

En ese contexto, desde la Comisión Económica para América Latina (CEPAL), un grupo de economistas impulsaron la conformación de un mercado regional, afirmando que el mismo permitiría que las empresas locales alcanzaran la dimensión óptima para aumentar su productividad a través de la especialización industrial y el incremento en la

5 Sebastián Sztulwark (2005) sostiene que el surgimiento del llamado "paradigma desarrollista latinoamericano" se debió a dos fenómenos complementarios. Por un lado, al proceso de cambio estructural que vivía la Región como respuesta al nuevo escenario económico de posguerra. Por el otro, al espacio abierto para pensar el estilo de desarrollo y los nuevos desafíos del proceso de industrialización que se presentaba en este nuevo escenario. 
demanda. En su influyente libro El desarrollo económico de la América Latina y algunos de sus principales problemas, publicado en 1949, Raúl Prebisch ${ }^{6}$ estableció entre las condiciones necesarias para el desarrollo industrial la conformación de un mercado en expansión y una mayor coordinación entre las economías de la Región. En este sentido, la Reunión Interamericana de 1957, celebrada en la ciudad de Buenos Aires, constituyó un hito en los procesos de integración subcontinental. En dicha reunión, la Organización de Estados Americanos no solo tomó conocimiento oficial de diversos proyectos elaborados por expertos de la CEPAL, sino también encomendó al organismo que trabajara en propuestas concretas para su implementación ${ }^{7}$ (Medina Valverde, 2002).

Por su parte, distintos gobiernos de la Región expresaban públicamente la necesidad de impulsar la integración de sus economías. En este marco, se destacaron las figuras del presidente chileno Jorge Alessandri (1958-1964) y de su par argentino Arturo Frondizi (1958-1962), los cuales compartían la convicción sobre la existencia de una estrecha relación entre estabilidad política y desarrollo económico, al igual que sobre la importancia que la integración latinoamericana tendría para la concreción de este último. En este sentido, el mandatario chileno expresaba su apoyo absoluto a la conformación de una zona de libre comercio en América Latina, enmarcando dicho proceso en la imperiosa necesidad de adecuar los medios para alcanzar y fortalecer los principios democráticos frente a lo que identificaba como "novedosas condiciones del mundo" (Medina Valverde, 2002, p. 261) ${ }^{8}$. Por su parte, el presidente Frondizi sostenía que América del Sur era el ámbito natural de la Argentina, tanto en virtud de la unidad religiosa, histórica y geográfica, como también de que el desarrollo material del país debía producirse junto al de la Región. En lo referido a la relación con Chile, afirmaba que debían sentarse las bases de un nuevo régimen de intercambio comercial, que armonizara el desarrollo industrial de ambos países, abriendo nuevas vías de comunicación y facilitando el desarrollo de las personas (Pelosi y Machinandiarena de Devoto, 2012, pp. 13-16). Finalmente, en el marco

$6 \quad$ Sobre la trayectoria de Raúl Prebisch y su aporte al desarrollismo latinoamericano, ver "Homenaje a Raúl Prebisch" en Revista CEPAL Número 75, diciembre de 2001, Santiago de Chile, pp. 7-114.

7 A comienzos de 1958, la CEPAL convocó a un grupo de trabajo para estudiar los principios básicos sobre los que debía asentarse un mercado Regional. Al año siguiente, delegados gubernamentales de Argentina, Brasil, Chile, Perú y Uruguay se reunieron en Lima para redactar un proyecto de zona de libre comercio, contemplando las recomendaciones elaboradas por el grupo de trabajo cepalino. A partir de entonces, este organismo promovió la actividad interestatal para conciliar los objetivos de largo plazo de la CEPAL con las medidas de adopción inmediata previstas por los distintos países de la Región (Medina Valverde, 2002).

8 Con motivo de la reunión del denominado “Comité de los 21", celebrada en Buenos Aires para estudiar los mecanismos más idóneos que permitan potenciar la prosperidad continental, Hernán Videla Lira sostuvo en su informe al Senado chileno que el desarrollo económico latinoamericano podía ser enfocado desde tres aspectos: como "problema de conciencia" de la civilización occidental; como una "necesidad imperiosa para la interdependencia económica mundial”, y como una “exigencia de seguridad del mundo libre" (Medina Valverde, 2002, p. 263). 
de este escenario dominado por gobiernos que, con distinta intensidad, se inscribían en la constelación desarrollista, se firmó en febrero de 1960 el Tratado de Montevideo, que dio origen a la Asociación Latinoamericana de Libre Comercio (ALALC) ${ }^{9}$.

En la prensa argentina, las noticias sobre la creación de la ALALC alcanzaron gran repercusión. Los principales diarios de ese país privilegiaron lecturas económicas sobre el acuerdo, apelando a enunciadores "expertos" para establecer tanto la potencialidad como la necesidad del proceso de integración. En el caso del diario Clarín, abiertamente identificado con los postulados desarrollistas, podía leerse al propio Raúl Prebisch, devenido en columnista del matutino, sentenciar que en México, Brasil, Argentina, Chile y Colombia, la etapa sustitutiva estaba próxima a agotarse y que la expansión de una industria más compleja requería superar una veintena de "compartimentos estancos" sin especialización ni "división racional del trabajo" ${ }^{10}$. En su espacio editorial, el diario abrevaba en el mito de la patria grande para sentar su posición en favor del acuerdo al afirmar que: "Latinoamericanismo es también nacionalismo. Pero del mejor"11. Inclusive un diario de tendencia liberal como La Nación, que por esos días advertía sobre el "peligro" de la pervivencia de "nacionalistas" y "dirigistas" en el gabinete nacional, celebraba la disposición de los países firmantes de la ALALC en promover una "gradual coordinación" de las políticas industriales ${ }^{12}$.

Las noticias sobre el acuerdo también tuvieron su impacto en la Norpatagonia. Para el Río Negro constituyó un tema por demás relevante, como quedó de manifiesto en la cantidad de artículos publicados como en la dimensión de sus titulares y el espacio asignado dentro de su superficie redaccional (Azcoitia, 2013). Al igual que en los diarios capitalinos, predominó en estas noticias un discurso de matriz desarrollista que destacaba la importancia de la integración regional. Quizá donde se expresó en forma más cabal esta posición fue a través de una serie de notas de opinión publicadas por el diario en el transcurso del mes febrero. El autor de dichos artículos fue Julio Raúl Rajneri, una reconocida figura de la política de la provincia y miembro de la familia propietaria del Río Negro, que por ese entonces se encontraba bajo la dirección de su hermano Fernando Rajneri hijo. Sin lugar a dudas, estos antecedentes refieren a una pluma que no podríamos

La Asociación estuvo conformada inicialmente por la Argentina, Chile, Brasil, Uruguay, México, Paraguay y Perú. En 1961 la suscribieron Colombia y Ecuador. Cinco y seis años después la ratificaron también Venezuela y Bolivia. El objetivo de estos acuerdos era la progresiva eliminación de aranceles en vista a la creación de una zona de libre comercio.

10 El mercado común y ritmo del desarrollo económico. (18 de febrero de 1960). Clarín, p. 4.

11 El mercado común en 9 razones. (23 de marzo de 1960). Clarín, p. 3.

12 Hacia la zona de libre comercio. (20 de febrero de 1960). La Nación, p. 6. 
caracterizar como la de un simple "columnista", sino que por el contrario, la asumimos como expresión de la voz institucional del diario (Azcoitia, 2013).

En estas notas, presentadas como reflexiones sobre su paso por un seminario organizado en la Universidad de Santiago de Chile, Rajneri expresaba un evidente optimismo sobre el futuro del proceso de integración, afirmando que los diferentes países de la Región cederían "sus soberanías nacionales en beneficio de una comunidad de países latinoamericanos", para agregar luego que esta unidad comenzaría en el "plano económico", desplazándose posteriormente al político ${ }^{13}$. En sus artículos sostenía que, ya sea a través de la libre empresa, mediante revoluciones populares o a través de la intensificación de los intercambios culturales, todos los disertantes del seminario coincidían en el carácter irrefrenable del proceso de integración. Adoptando la tesis de la "coexistencia competitiva", el autor afirmaba que la Guerra Fría se convertiría en "una competencia 'deportiva' por el desarrollo económico", al tiempo que advertía que "de no ponerse freno a la miseria, al atraso y al subdesarrollo", se crearían en América Latina las condiciones para "desórdenes sociales de imprevisibles consecuencias". Para reforzar esta posición, Rajneri apeló al principio de autoridad al evocar las palabras del político chileno Radomiro Tomic ${ }^{14}$, quien afirmaba que la Región enfrentaba un dilema: "O los países latinoamericanos se unen en una sola comunidad de naciones y encuentran la respuesta adecuada mediante la cooperación democrática o la otra alternativa (...) será viable, por la vía de la dictadura”. De esta forma introducía una lectura del proceso en clave política que establecía una secuencia causal entre integración, desarrollo económico y estabilidad institucional. En esta línea, la saga de escritos de Rajneri concluía destacando la postura "americanista" de Brasil y Chile, a la vez que advertía sobre la necesidad de la Argentina de "acentuar su interés latinoamericano y contribuir a estas aspiraciones o aislada y absorta en su exclusivo problema nacional, renunciará a obtener por la vía más factible la concreción de las aspiraciones de progreso de su pueblo"15. Si bien la advertencia comprendía al conjunto de la dirigencia política, debemos señalar que el Río Negro fue un diario crítico hacia la gestión de Frondizi, entre otros motivos por la identificación de los Rajneri con la Unión Cívica Radical del Pueblo (UCRP), facción del radicalismo que se oponía a la Unión Cívica Radical Intransigente (UCRI), en la cual se encuadraba el presidente. Esta confrontación no respondía solo a los alineamientos en el

13 El impacto de los acontecimientos internacionales en América Latina. (8 de febrero de 1960). Río Negro, p. 4.

14 Político chileno democratacristiano, nombrado embajador en los EE.UU. durante el gobierno de Eduardo Frei (1964-1970) y candidato a presidente por su partido en las elecciones de 1970 en las que triunfó Salvador Allende.

15 El impacto de los acontecimientos internacionales en América Latina. (8 de febrero de 1960). Río Negro, p. 4.

104 Si Somos Americanos. Revista de Estudios Transfronterizos 
escenario nacional, sino también a las disputas regionales que se abrieron en el marco de la provincialización de Río Negro ${ }^{16}$ (Azcoitia, 2013).

Con este tipo de artículos se evidenciaba en el Río Negro la pervivencia de la "avanzada civilizatoria"17 imaginada por la prensa patagónica a lo largo de la etapa territoriana (Prislei, 2001, p. 13). Esta continuidad se plasmaba, en la década del sesenta y setenta, a través de notas, columnas y editoriales que acercaban a los lectores a los temas de orden político, económico, social y cultural que hegemonizaban la agenda informativa a escala continental y mundial. De esta forma, la pertenencia que el diario pretendía generar no se limitaba ya a un colectivo local o nacional, como lo había sido durante el período territoriano, sino que incluía también a Latinoamérica y a Occidente como nuevas referencias que se integraban a esa identidad que el Río Negro pretendía modelar. Asimismo, a comienzos de la década del sesenta, los debates en torno al desarrollo y la modernización económica no resultaban ajenos a la población norpatagónica. En este sentido, los estudios sobre la factibilidad de proyectos estratégicos, como la construcción de la represa hidroeléctrica del Chocón o la explotación minera de Sierra Grande, propiciaron discusiones en torno al tipo de desarrollo que debía impulsarse en la región, los cuales no solo contaron con la intervención de diversos actores locales y nacionales, sino también con la decisiva participación de consultoras extranjeras, organismos de crédito como el Banco Interamericano de Desarrollo y el Banco Mundial e incluso de la CEPAL (Azcoitia y Núñez, 2013, 2014; Bandieri y Blanco, 2012).

16 En las elecciones del 28 de julio de 1957, los ciudadanos rionegrinos votaron a sus convencionales para redactar y sancionar la Constitución provincial. En este marco volvieron a generarse las históricas disputas entra las ciudades de General Roca, Choele Choel y Viedma, tres aspirantes a convertirse en capital de la novel provincia. En este escenario, la lucha de intereses locales también se canalizó a través de las disputas generadas en torno a las distintas fracciones en que se dividió el radicalismo luego del derrocamiento de Juan Domingo Perón (Iuorno, 2008). En el marco de la Convención Constituyente, las adhesiones hacia una u otra ciudad respondieron a los alineamientos partidarios, encolumnándose los diputados de la UCRP tras la propuesta de General Roca mientras que los representantes de la UCRI postularon a Viedma como capital. La férrea defensa de los intereses de esta región provocó un cisma dentro del radicalismo intransigente, generando la conformación para las elecciones de 1958 de la lista verde, expresión de la UCRI de General Roca. La falta de acuerdo llevó a la convención a aplazar la decisión por un lapso de cinco años, manteniendo mientras tanto a Viedma como capital provisional. Esta situación persistió hasta el 20 de octubre de 1973, momento en el que se sancionó la ley 852 que declaraba a Viedma como capital de la Provincia de Río Negro (Navarro Floria y Nicoletti, 2001).

17 Leticia Prislei sostiene que desde fines del siglo XIX, los periódicos patagónicos se imaginaron como elemento constitutivo de la "avanzada civilizatoria", encabezada por el Estado nacional, buscando erigirse en organizadores de la trama cultural y en generadores de los modos de imaginar la pertenencia a un colectivo regional y nacional (2001, p. 13). 
El predominio del discurso integracionista no solo se manifestó en las noticias referidas a la firma de acuerdos regionales, sino también en aquellas que tuvieron a Chile o a las relaciones binacionales como tema central. Un ejemplo de ello fue la propuesta de desarme impulsada por Jorge Alessandri ${ }^{18}$, la cual motivó que el Río Negro dedicara un editorial pletórico de expresiones elogiosas hacia el presidente chileno, en cuyo párrafo final realizaba una breve caracterización del contexto regional de principio de los sesenta:

Es evidente que las repúblicas latinoamericanas, que poseen una acendrada vocación pacifista y que aún deben comprometer todos los esfuerzos y todos los ahorros en obras que mejoren las condiciones de vida de sus pueblos, sienten más que nunca la necesidad de liberarse del peso que en los presupuestos nacionales descargan los gastos militares. Tienen más necesidad de industrias que de ejércitos; los ejércitos, lejos de robustecerlas o fortificarlas, originan su debilitamiento y hasta su anemia económica ${ }^{19}$.

Cabe destacar que en momentos en que, con intensidad variable, se incrementaba la intervención de las Fuerzas Armadas en la vida política latinoamericana, el diario las construía como un problema para la Región situándolas como antagónicas a su desarrollo económico. Desde esta perspectiva, la "vocación pacifista" de estas repúblicas no solo tornaba obsoletos los presupuestos en armamento, sino que, implícitamente, favorecía el proceso de integración al priorizar los acuerdos por sobre las hipótesis de conflicto castrenses. En los artículos que ya hemos analizado, Julio Rajneri también había advertido sobre la "estéril y agobiante" carrera armamentista que costaba anualmente dos mil millones de dólares, los cuales, según Rajneri, deberían haberse destinado a impulsar el desarrollo de la Región ${ }^{20}$.

Las entrevistas entre los presidentes de ambos países configuraron otro escenario en el que predominaron expresiones favorables a la integración. Las noticias sobre el encuentro de Viña del Mar entre Arturo Frondizi y Jorge Alessandri destacaron tanto la afinidad personal, la cual se desprendía de la gestualidad desplegada por ambos mandatarios, como los términos en que se había redactado el documento final ${ }^{21}$. En las páginas del Río Negro, el presidente chileno emergía como un enunciador concesivo y amigable,

18 Sostiene Cristian Medina Valverde que existe consenso en destacar esta iniciativa, denominada "Doctrina Alessandri", como lo más relevante en materia de política exterior durante el gobierno de Jorge Alessandri. En noviembre de 1959 y en su intervención ante la OEA, en 1962, el presidente chileno señaló que su país había puesto énfasis en llamar a la conciencia del continente a favor de una lucha contra el armamentismo (2002, p. 224).

20 El impacto de los acontecimientos internacionales en América Latina. (7 de febrero de 1960). Río Negro, p. 4.

21 Cordialmente recibieron al Dr. Frondizi en Chile. (10 de septiembre de 1961). Río Negro, p. 1. 
caracterizando la relación binacional en términos de potencialidad positiva. En este marco, los aspectos conflictivos fueron desplazados hacia el escenario latinoamericano, centrándose fundamentalmente en la llamada "cuestión cubana". En estos discursos, el vínculo entre Argentina y Chile no se presentaba en clave de disputa fronteriza sino que, por el contrario, se hacía hincapié en la cooperación como rasgo distintivo del pasado y del presente. Podría pensarse, no sin razón, que expresiones de este tipo respondían, en parte, a fórmulas protocolares propias del registro diplomático, sin embargo, lo que resulta relevante para este artículo es que el diario estructuró su discurso sobre la base de estos argumentos, sin habilitar espacios para voces que lo cuestionaran o matizasen (Azcoitia, 2013).

Finalmente, la Norpatagonia también formó parte del temario de la entrevista pero desde una dimensión distinta. A través de los proyectos de mejora de caminos internacionales, referido principalmente al paso Puyehue entre Bariloche y Osorno, y de la coordinación de planes de turismo, la integración adquirió para los lectores del diario un carácter más concreto y cercano.

\section{Las tensiones entre la profundización de la integración y el conflicto territorial}

Con la llegada de Arturo Illia (1963-1966) a la presidencia argentina y el posterior triunfo de Eduardo Frei (1964-1970) en Chile, se generó un clima propicio para estrechar los vínculos binacionales. Ambos gobiernos se proponían implementar un programa económico de base industrialista con fuerte influencia cepalina, en el marco de políticas reformistas en materia social (Aronskind, 2003; Mires, 1989; Rapoport, 2005). Compartieron también un fuerte sentido latinoamericanista que se cristalizó en las demandas por la profundización de la integración Regional, la cual también permitiría disminuir la injerencia de Washington y contener la creciente influencia de la dictadura brasileña (Cisneros y Escudé, 2000; Medina Valverde, 2002; Simonoff, 2007). En este contexto, se amplificó el campo semántico de la integración, otorgando a la dimensión política y cultural una relevancia mayor que la observada durante las presidencias de Frondizi y Alessandri.

El Río Negro plasmó en las noticias sobre la entrevista entre Illia y Frei, realizada en 1965 en la ciudad de Mendoza, esta perspectiva que entendía la integración como un proceso que debía comprender todas las dimensiones de la realidad (Devés, 2003). En 
sus páginas, los discursos presidenciales inscribían dicho encuentro en una genealogía que comenzaba con las "gestas independentistas", proyectándose después hacia un futuro signado por el proceso de integración ${ }^{22}$. Evocando las palabras de la poetisa Gabriela Mistral, Eduardo Frei afirmaba que "los tiempos vuelven como las mareas", para sostener luego que la trascendencia de la coyuntura actual no era "menor que aquella que se presentó en la hora de la independencia"23. La integración se convertía así en un paso imprescindible en el camino de la definitiva liberación.

Por su parte, el discurso de la prensa chilena que se recortaba de las páginas del diario rionegrino construía un efecto de unanimismo en torno al proceso de integración. Mientras El Mercurio resaltaba la voluntad de "llegar a una efectiva complementación", calificando al encuentro como "un impulso a la integración latinoamericana", La Nación sostenía que el momento estaba marcado por "el imperativo de una integración americana que no puede retardarse más" ${ }^{24}$. En un editorial reproducido por el Río Negro, podía leerse a El Mercurio celebrando la decisión de ambos gobiernos de "suspender las divergencias de orden limítrofe" para "entregarse (...) a tareas y responsabilidades que las actuales circunstancias latinoamericanas hacen cada vez más trascendentales y urgentes", como la defensa hemisférica ante el "peligro de la agresión comunista en todas sus formas" ${ }^{\prime 2}$. De esta manera, el diario de la familia Edwards introducía un nuevo sentido de la integración que, como veremos, anticipaba en parte al que implementaría la dictadura argentina a partir de 1966.

Una vez más, al referirse al espacio norpatagónico, las noticias sobre la integración abandonaron este nivel de abstracción para adquirir una dimensión más concreta, referida a acuerdos comerciales y obras de infraestructura. En este sentido, el diario destacó los proyectos sobre la conformación de un "circuito turístico de montaña" y también sobre la construcción del camino Bariloche-Puerto Montt, tendientes a profundizar la complementación económica ${ }^{26}$. Pablo Lacoste $(1996,2013)$ nos recuerda que en el caso de la región de los Andes centrales, en estos años también se reactivó el proyecto de electrificación del Ferrocarril Trasandino, interrumpido tras el golpe de 1962 luego del impulso inicial que recibiera durante la gestión de Frondizi, y se alcanzó la aprobación de leyes tendientes a potenciar la conectividad vial entre la Argentina y Chile.

\footnotetext{
Cordial recibimiento tributose a Frei en el encuentro con Illia. (29 de octubre de 1965). Río Negro, p. 1.

Los elocuentes discursos de Illia-Frei. (30 de octubre de 1965). Río Negro, p. 1.

Comentario de la prensa de Chile sobre la entrevista Illia-Frei. (2 de noviembre de 1965). Río Negro, p. 11.

Comentan la futura entrevista de los presidentes Illia y Frei. (27 de septiembre de 1965). Río Negro, p. 11.

Gobernadores de provincias fronterizas con Chile. (31 de octubre de 1965). Río Negro, p. 1.
} 
La relevancia asignada por el Río Negro a la visita del presidente Frei y el tratamiento informativo dispensado no presentaron diferencias significativas con la cobertura realizada por los principales medios de la capital argentina. Los diarios La Nación y Clarín destacaron el "espíritu americanista" que impulsó el encuentro, remarcando la significación de "la integración económica de América Latina y la política de complementación entre la Argentina y Chile"27. Las crónicas publicadas por estos medios resaltaban también el "entusiasmo popular" que "desbordó las calles" como "muestra de amistad entre ambos pueblos”28. En los días previos a la entrevista, el Río Negro publicó un editorial con motivo del aniversario de la independencia de Chile ${ }^{29}$, destacando que la unidad entre ambos países no solo se cimentaba en un pasado "glorioso" signado por las luchas independentistas, o en la extensa geografía que nos avecinaba en el extremo sur del mundo, sino también en la numerosa presencia de "pacíficos" trabajadores, claves en el desarrollo de las actividades económicas esenciales para la zona del Alto Valle ${ }^{30}$. De esta manera, la representación de Chile añadía al "espíritu americanista" que trazaba un pasado y futuro comunes, una dimensión más cotidiana para los lectores del diario vinculada al quehacer económico de la región ${ }^{31}$. En este punto, resulta pertinente señalar que durante la década del cincuenta, el crecimiento de la fruticultura excedió la capacidad de trabajo de la unidad familiar. De esta manera, la demanda creciente de los productores de la región se cubrió con trabajadores temporal trasandinos, principalmente entre los meses de diciembre y marzo en los que se realizaba la cosecha (Trpin, 2004).

El discurso integracionista predominante en las páginas de Río Negro situaba el "conflicto" en el orden de lo "circunstancial" o del "absurdo", mientras que el entendimiento parecía expresar la propia naturaleza de relaciones entre Chile y la Argentina. En esta matriz de sentido, la "cooperación" adquiría una gran densidad histórica teniendo como anclaje el momento mítico del nacimiento de la Nación con las luchas independentistas. Esta forma de concebir la integración tornaba los problemas fronterizos en artificiales e inoportunos,

27 Reunión en Mendoza y ley de presupuesto. (25 de octubre de 1965). La Nación, p. 1.

28 Apoteósica bienvenida se tributó a Frei en Mendoza. (29 de octubre de 1965). Clarín, p. 14; Calurosa acogida se tributó en Mendoza a los Dres. Illia y Frei. (29 de octubre de 1965). La Nación, p. 1; Entusiasmo popular. (29 de octubre de 1965). La Nación, p. 18.

29 Todos los años, el diario realizaba una amplia cobertura de los actos organizados por la colectividad chilena en la región, fundamentalmente en las localidades del alto valle, sin embargo, no era habitual que acompañase dichas notas con un editorial.

30 Susana Bandieri y Gabriela Blanco sostienen que el cultivo intensivo de peras y manzanas fue otorgando una identidad socioeconómica al área de la Norpatagonia ubicada en los valles superior del río Negro e inferiores de sus afluentes, los ríos Limay y Neuquén, donde se conformó una región productiva que se extiende por encima de los límites políticos entre las provincias de Río Negro y Neuquén, conocida mundialmente como Alto Valle de Río Negro (2015, p. 143).

31 Independencia de Chile. (18 de septiembre de 1965). Río Negro, p. 2. 
en rémoras del pasado que el círculo virtuoso de la integración y el entendimiento de los pueblos permitiría superar (Medina Valverde, 2002, p. 289).

A pesar de ello, el conflicto suscitado por el incidente de "Laguna del Desierto" evidenció que tanto la cuestión territorial como el temor al sempiterno "enemigo expansionista" no solo conservaban vigencia en el universo castrense, sino también su capacidad de influir sobre la opinión pública. Si bien el documento final del encuentro de Mendoza únicamente había hecho una breve referencia general a las cuestiones limítrofes, unos días después emergió con fuerza esta tensión latente al conocerse la detención de un poblador argentino por parte de integrantes del cuerpo de Carabineros. Este hecho ocurrido en la zona denominada "Laguna del Desierto" desató un serio conflicto diplomático que se profundizó con el posterior enfrentamiento entre gendarmes y carabineros, el cual arrojó como saldo la muerte de un oficial chileno. A pesar del clima de cordialidad en el que se había desarrollado la entrevista entre Illia y Frei, los sectores nacionalistas lanzaron una fuerte campaña, a la que se plegó una parte significativa de la prensa, azuzando a la opinión pública sobre las cuestiones fronterizas pendientes con Chile (Cisneros y Escudé, 2000; Mazzei, 2012; Valenzuela Lafourcade, 1999). Luego del enfrentamiento que costó la vida de un oficial chileno, el diario Clarín tituló en su primera plana: "Gendarmería repelió un ataque sorpresivo de los carabineros". Prácticamente en los mismos términos, La Nación sostenía que "Gendarmería repelió en el sur una agresión chilena”32. Como se observa aquí, ambos medios optaron por titulares que establecían taxativamente que el incidente se había producido en suelo argentino y que los chilenos eran los agresores. Publicaron también numerosos artículos que daban cuenta de movimientos de tropas en la frontera y de la proliferación de "manifestaciones antiargentinas" en Chile, de las cuales responsabilizaban a la prensa trasandina por inflamar las pasiones con "palabras insensatamente belicosas" ${ }^{33}$.

En el caso del Río Negro, en sus páginas se evidenció la tensión entre enunciadores mesurados y conciliadores, con otros "beligerantes" que apelaban a un léxico propio de los partes de guerra (Azcoitia, 2016). Sin embargo, pese a que esta confrontación fue

32 Gendarmería repelió en el sur una agresión chilena. (8 de noviembre de 1965). La Nación, p. 1; Agresión chilena en Laguna del Desierto. (9 de noviembre de 1965). Clarín, p. 14; Los actos de violación de nuestra frontera. (14 de noviembre de 1965). La Nación, p. 1;La violación de nuestro suelo provocó el choque fronterizo". (17 de noviembre de 1965). La Nación, p. 1; Expresiones por la defensa de la soberanía argentina. (16 de noviembre de 1965). La Nación, p. 15.

33 Chile: decrece la tensión oficial pero siguen las manifestaciones callejeras. (10 de noviembre de 1965). Clarín, p. 14; Hubo ayer nuevas manifestaciones en el país trasandino. 10 de noviembre de 1965). La Nación, p. 20; Argentinos bajo protección policial en el sur de Chile. (13 de noviembre de 1965). La Nación, p. 1; Hubo denuncias de quema de una bandera argentina en Chile. (13 de noviembre de 1965). La Nación, p. 14; Chile extrema las medidas para evitar más atentados contra nuestra embajada. (12 de noviembre de 1965). Clarín, p. 22. 
profundizándose a lo largo de los meses subsiguientes, las noticias sobre la cumbre de cancilleres realizada en Río de Janeiro parecían propiciar el retorno de la integración como tema estructurante de la agenda binacional. En ellas se destacaba el proyecto presentado por la delegación chilena, caracterizándolo como el "más detallado y ambicioso [...] tratado interamericano de Solidaridad Económica" ${ }^{34}$. En este escenario, el canciller argentino Miguel Ángel Zavala Ortiz afirmó que "el nacionalismo aislado" conduciría al fracaso, mientras que "el nacionalismo integrado" constituía "la solución a nuestro alcance", volviendo a situar las relaciones entre ambos países en el mismo horizonte discursivo que había prevalecido en los análisis y notas sobre el encuentro de Mendoza ${ }^{35}$.

Unos días antes, el Río Negro había apelado en su espacio editorial a los "seculares lazos de amistad fundados en la comunidad de origen" para reinstalar, en un contexto conflictivo dominado por el nacionalismo territorial ${ }^{36}$, la idea de la unidad como imperativo histórico. Para el diario, el destino de la Argentina no se jugaba en la disputa por "pequeñas áreas" sino en la profundización de los procesos de integración regional ${ }^{37}$. Consideramos que esta posición asumida por la empresa periodística conjugaba tanto los tradicionales vínculos entre la Norpatagonia y Chile; como las expectativas de importantes sectores económicos locales en torno a las posibilidades de acrecentar su rentabilidad a través del mercado trasandino. Asimismo, cabe recordar que este mismo sector dependía de la fuerza de trabajo que proveían los migrantes chilenos, la cual podía verse entorpecida ante un conflicto fronterizo. Finalmente, otra arista a tener en cuenta para analizar la posición del diario es el explícito apoyo brindado por este a las principales líneas políticas impulsadas por el presidente Arturo Illia, hombre surgido de las filas de la UCRP (Azcoitia, 2016).

Si bien el conflicto de "Laguna del Desierto" finalmente alcanzó una resolución pacífica, el mismo evidenció la tensión creciente entre el integracionsimo americanista y la presión del nacionalismo territorial que recorría el campo por el que circulaban los discursos sobre las relaciones argentino-chilenas.

34 Argentina, Chile y Brasil presentaron respectivamente proyectos en la conferencia de cancilleres. (22 de noviembre de 1965). Río Negro, p. 1.

35 La posición argentina fue expuesta en Río de Janeiro por el Dr. Zavala Ortiz. (24 de noviembre de 1965). Río Negro, p. 1 .

36 Para el encargado de negocios de la embajada chilena, durante el conflicto por el incidente de Laguna del Desierto se produjo la "mayor reacción pública argentina" en la historia de las disputas limítrofes, refiriéndose al rol que asumieron los medios de comunicación en el marco de dicho incidente (Valenzuela Lafourcade, 1999, p. 82).

37 El incidente fronterizo. (11 de noviembre de 1965). Río Negro, p. 2. 


\section{La "Revolución Argentina” y la integración de las fronteras ideológicas}

En junio de 1966, los militares argentinos abandonaron el rol tutelar ejercido hasta ese momento e intentaron implantar un sistema autoritario estable dominado por las Fuerzas Armadas (Cavarozzi, 2009). Enmarcada en la Doctrina de Seguridad Nacional ${ }^{38}$, la dictadura de Juan Carlos Onganía (1966-1970) impuso un shock autoritario ${ }^{39}$ tendiente a quebrar la capacidad defensiva de los sectores populares, para así garantizar el patrón de acumulación de la fracción superior de una burguesía altamente oligopólica y trasnacionalizada (O’Donnell, 2010).

En materia de política exterior, la dictadura comenzó a acercarse a su par brasileña ${ }^{40}$, con la cual compartían el alineamiento con los Estados Unidos, la voluntad de conformar una alianza militar sobre la base de la tesis de la "frontera ideológica", junto con la idea de relanzar la ALALC bajo un esquema de integración flexible ${ }^{41}$ (Rapoport, 2005; Zapata y Zurita, 2005). En este escenario, el presidente Eduardo Frei comprendió que debía fortalecer su alianza con los gobiernos democráticos de la Región para evitar el aislamiento político en el Cono Sur ${ }^{42}$ (Medina Valverde, 2002; Valenzuela Lafourcade, 1999).

Este cambio en las relaciones con Chile ${ }^{43}$ se plasmó rápidamente en la superficie redaccional del Río Negro a través noticias que daban cuenta tanto del desplazamiento

38 Durante los años de la Guerra Fría, la Doctrina de Seguridad Nacional se estructuró en función del enfrentamiento entre el "comunismo internacional apátrida" y el "mundo occidental y cristiano". En el marco de este conflicto que se desarrollaba más allá de las fronteras estatales, las Fuerzas Armadas transformaron a la nación en "teatro de operaciones", desplegando su potencial represivo sobre el "enemigo interior", un otro ideológico que al "mimetizarse" con el resto de la población, debía ser identificado, excluido y posteriormente eliminado (Ansaldi, 2004; Mazzei, 2012).

39 En el marco de esta dictadura, los partidos políticos fueron prohibidos, las universidades intervenidas y el "Estatuto de la Revolución Argentina" adquirió un rango superior al de la Constitución Nacional.

40 Este acercamiento incluso propició que en febrero de 1967, la dictadura brasileña propusiera a la Argentina conformar una unión aduanera que abarcara, separadamente, los sectores siderúrgico, petroquímico y agrícola (Rapoport, 2005).

$41 \quad$ En la conferencia de la OEA de 1967, la Argentina propuso la institucionalización de un Comité Consultivo de Defensa como órgano militar de la Organización. La propuesta apuntaba a dar cabida a los militares en la OEA para intervenir discrecionalmente en cuestiones de seguridad interna de los países miembros (Rapoport, 2005).

42 Medina Valverde (2002) sostiene que para los regímenes militares de Brasil y la Argentina, el programa reformista de la democracia cristiana era de tipo izquierdizante y por tanto divergente de la ortodoxia doctrinaria del pensamiento militar. Por su parte, para Joaquin Fermandois y Michelle León Hulaud (2005), lo que generaba desconfianza no era el gobierno de Frei, del cual la dictadura argentina tenía plena conciencia que no correspondía a ningún radicalismo político, sino el "sistema” político chileno.

43 Mario Valenzuela Lafourcade sostiene que el nuevo canciller argentino, Nicanor Costa Méndez, aplicó una política "dura" con Chile al que consideraba un vecino más débil que era necesario "poner en su lugar" (1999, p.

\section{Si Somos Americanos. Revista de Estudios Transfronterizos}


de la integración por los diferendos territoriales como problemática central de la agenda diplomática binacional, como del progresivo distanciamiento entre ambos gobiernos que estaba en curso. En este contexto, comenzaron a circular por las páginas del diario dos concepciones sobre la integración regional que se diferenciaban con claridad, tanto por los alcances como por la naturaleza de dicho proceso. Por un lado, las noticias sobre la firma de la "Declaración de Bogotá" daban cuenta de gobiernos que adherían a un documento concebido como "el primer paso concreto hacia la integración económica y la unidad latinoamericana", la cual estaba llamada a marcar en la región el nacimiento de una "nueva etapa" dominada por la "Revolución Democrática"44. Esta declaración emitida por los presidentes de Chile, Colombia y Venezuela no solo señalaba la necesidad de “...acelerar la unidad...”, sino también la de impulsar el desarme, respaldar la política de no intervención y afianzar la democracia representativa, en tanto "factores de desarrollo" ${ }^{45}$. Cabe señalar que el Río Negro publicó en su totalidad dicha declaración, a la vez que en sus páginas emergía la figura de Eduardo Frei no solo como el principal promotor de los acuerdos, sino también como un presidente de gran popularidad en la Región ${ }^{46}$. Sin embargo, de las noticias publicadas por el diario también se desprendía el recelo que despertaban en la dictadura argentina estos esquemas de integración que, desde la perspectiva castrense, implicaban una pérdida de "soberanía" 47 . En este sentido, la cobertura informativa sobre la cumbre de la ALALC de 1966 expuso abiertamente la confrontación entre la posición de la delegación chilena, la cual bogaba por acelerar la integración, y la sostenida por Argentina y Brasil, planteando la necesidad de seguir un proceso "lento y gradual", a la vez que desacreditaba la postura trasandina por considerarla carente de "realismo" 48.

185). En este sentido, cabe señalar que durante la primera etapa de dictadura, el Ateneo de la República, un club político formado por nacionalistas católicos, aportó numerosos cuadros, principalmente para los ministerios del Interior y Relaciones Exteriores. Este último lo integraban: Costa Méndez (canciller); Jorge Mazzinghi (vicecanciller); Máximo Etchecopar (jefe de servicio exterior) y el inspirador del grupo, Mario Amadeo (embajador en Brasil) (Mazzei, 2012).

44 Informaron sobre conclusiones de la reunión Frei, Lleras Restrepo y Leoni. (18 de agosto de 1966). Río Negro, p. 15.

45 Los representantes de los 5 países sentaron bases para la integración de Latinoamérica. (19 de agosto de 1966). Río Negro, p. 9.

46 Una gira integracionista hará Eduardo Frei por tres países latinoamericanos. (11 de agosto de 1966). Río Negro, p. 8 .

47 Expondremos en la ALALC las ideas que expresó el presidente de la nación, dijo Costa Méndez. (7 de diciembre de 1966). Río Negro, p. 7.

48 Chile no firmó el protocolo que institucionaliza el consejo permanente de cancilleres de la ALALC. (13 de diciembre de 1966). Río Negro, p. 2. 
De esta forma, las páginas de Río Negro (re)presentaban a la Argentina y Chile como dos formas antagónicas de concebir la inserción regional. Para esta última era necesario acelerar el proceso de integración, enfatizando su dimensión política al establecer el respeto a la autodeterminación de los pueblos, el desarme y la vigencia plena de la democracia representativa como condición necesaria para alcanzar el desarrollo. Por su parte, la dictadura argentina propugnaba por una integración "lenta", centrada únicamente en los aspectos económicos, resolviendo solo con el Brasil la dimensión política de su inserción regional. En este sentido, resultaban por demás esclarecedoras las afirmaciones del canciller Juracy Magalhaes sobre la "estrecha colaboración" que existía entre Brasilia y Buenos Aires "respecto de la cuestión de la seguridad colectiva en el hemisferio", dado que ambos gobiernos habían manifestado "posiciones claras y coincidentes acerca de la lucha contra la infiltración Castro-comunista en el continente" ${ }^{49}$. Recurriendo a una agencia extranjera como fuente, el diario rionegrino destacaba la importancia de la "Declaración de Bogotá" no solo por el impulso que pretendía otorgar al proceso de integración, sino también por constituir un "contrapeso" a las iniciativas de "la Cuenca del Río de la Plata" integrada por los gobierno brasileño y argentino ${ }^{50}$. En suma, en las páginas del Río Negro los principios de autodeterminación y democracia sobre los que se articulaban el discurso del gobierno reformista chileno confrontaban abiertamente con la noción de "seguridad colectiva" inspirada en la Doctrina de Seguridad Nacional, que impulsaban las dictaduras de Argentina y Brasil.

Cabe destacar que frente a estos dos paradigmas que parecían disputarse los alineamientos regionales, el diario Río Negro mantuvo la línea editorial sostenida en los años precedentes, ubicándose más cerca de la postura encarnada por el gobierno trasandino que la sostenida por la dictadura de su país. Este posicionamiento se desprendía tanto de las numerosas noticias favorables hacia las iniciativas de Eduardo Frei, como de las críticas hacia la orientación general del plan económico implementado por la dictadura, a los controles de prensa y a las medidas adoptadas para combatir a la "subversión", sin atacar lo que el Río Negro entendía como su causa principal: el subdesarrollo ${ }^{51}$. Sin embargo, al tiempo que el diario mantenía su línea editorial respecto a la integración, en otras zonas del discurso referido a Chile comenzaron a evidenciarse profundos quiebres. Como hemos mencionado, la centralidad que empezaban a adquirir los conflictos limítrofes en la agenda binacional estuvo acompañada por narrativas xenófobas y estigmatizantes que circularon profusamente en la Norpatagonia, (re)presentando a los migrantes chilenos,

49 Sobre la seguridad colectiva de América tratarán Costa Méndez y Juracy Magalahes. (15 de octubre de 1966). Río Negro, p. 7.

50 Frei tomaría represalias contra la oposición. (19 de enero de 1947). Río Negro, p. 4.

51 Eliminar la pobreza no la gente. (25 de octibre de 1967). Río Negro, p. 10.

\section{Si Somos Americanos. Revista de Estudios Transfronterizos}


entre otras cosas, como "analfabetos" y "promiscuos", sindicándolos como responsables de diversos problemas por los que atravesaba la región (Baeza y Lagos, 2016; Núñez y Barelli, 2013). En este contexto, la opinión en favor de la migración chilena que el Río Negro había mostrado hasta ese momento comenzó a matizarse. En algunos de sus editoriales ${ }^{52}$, la migración fue (re)presentada como un fenómeno masivo e incontrolable que alteraba la fisonomía social de una región que el diario pretendía modelar a través de su prédica cotidiana. Resulta probable, y complementario de lo señalado anteriormente, que también intentara hacerse eco de lo que percibía como cierto malestar de sus lectores sobre esa presencia "clandestina" de "extranjeros". A pesar de ello, el Río Negro no trepidó en reclamar a las autoridades correspondientes que facilitaran el ingreso de "braceros chilenos" que "venden su trabajo a nuestros productores frutícolas" ${ }^{3}$. Es probable que la posición sostenida por el diario respondiera a la demanda de los pequeños y medianos productores, necesitados de disminuir sus costos durante los meses de cosecha, en un contexto que se les presentaba cada vez más adverso, debido al creciente proceso de innovación tecnológica y a la caída de los precios internacionales de las peras y manzanas. Este escenario propició en los sesenta que las empresas que controlaban el empaque y frío de la fruta comenzaran a incursionar en la producción, favoreciendo el proceso de concentración de capital (Bandieri y Blanco, 2015, p. 162).

En este punto, resulta importante señalar que el discurso antichileno que comenzaba a fortalecerse cada vez más, circuló por el diario junto con otras noticias que daban cuenta de la persistencia de los fluidos intercambios económicos y culturales que existieron históricamente entre la Patagonia argentina y el sur chileno. Sin embargo, cabe aclarar que fueron actores particulares y organizaciones de la sociedad civil quienes se constituyeron en protagonistas de dichos intercambios, desapareciendo así la instancia estatal como articuladora de esos vínculos. Como hemos visto, esto marcaba un profundo cambio en relación con los años analizados previos al golpe de 1966. Asimismo, los trabajos de Pablo Lacoste nos permiten afirmar que este protagonismo no fue una particularidad norpatagónica, sino que constituyó una reacción frecuente en zonas estrechamente vinculadas con Chile. En la región de Cuyo, la decisión de la dictadura de paralizar proyectos, como la electrificación del Ferrocarril Trasandino, las obras del paso El Portillo Argentino-Piuquenes y del sistema Pehuenche ${ }^{54}$, encontró en la sociedad civil cuyana y su prensa a un defensor del "espíritu integracionista de los pueblos" $(1996,1998)$.

52 Radicación de extranjeros. (28 de noviembre de 1966). Río Negro, p. 10.

53 Criterio inflexible sobre radicación. (21 de diciembre de 1966). Río Negro, p. 10.

54 Solo se mantuvo en pie la construcción de la ruta por el Cristo Redentor debido a los compromisos asumidos con poderosos organismos financieros internacionales. Ante la imposibilidad de obturar este proyecto, la dictadura justificó su continuidad afirmando: “Un paso y controlado" (Lacoste, 1998, p. 122). 


\section{La integración durante el "pluralismo ideológico"}

A pesar del aparente clima de paz social impuesto por la "Revolución Argentina", hacia fines de 1968 comenzaron a producirse una serie de conflictos que revelaron la creciente combatividad y politización del movimiento obrero y estudiantil, los cuales erosionaron la figura de Onganía como garante del orden público ${ }^{55}$ (Pozzi y Schneider, 2000). Al mismo tiempo, el panorama internacional tampoco se presentaba demasiado alentador para la dictadura. La estrategia norteamericana de convertir a los ejércitos de la Región solo en fuerzas eficaces para la lucha antiguerrillera confrontaba con la intención de las Fuerzas Armadas de adquirir equipamiento avanzado para la guerra convencional ${ }^{56}$ (Rapoport, 2005, p. 524). En este complejo escenario, la dictadura argentina inició un acercamiento hacia Chile en busca de un socio que apoyara las negociaciones con los EE.UU. y contribuyera a la vez a equilibrar el creciente poder que la dictadura brasileña estaba adquiriendo en la Región ${ }^{57 .}$

En las páginas del diario rionegrino, los primeros indicios de este cambio en las relaciones binacionales comenzaron a percibirse hacia el final del gobierno de Juan Carlos Onganía. En este sentido, las noticias sobre el viaje del dictador argentino a Chile para inaugurar la autopista Mendoza-Valparaíso destacaban tanto la voluntad de los mandatarios de "desarrollar una acción latinoamericana conjunta", como la de respetar en forma irrestricta el "derecho de cada nación a su cultura y a su imagen propia, a su destino histórico y a las formas de organización política que adopten para conseguirlo" 58 . Para dimensionar la profundidad de este cambio, no solo debemos tener en cuenta la pretensión inicial de

55 Sebastián Carassai (2013) muestra que buena parte de la prensa nacional percibía un clima de calma y paz social que se esfumó a fines de mayo de 1969 con el estallido del Cordobazo.

56 Este alineamiento encontró sus límites en el ámbito estratégico, la negativa de la dictadura argentina a firmar los tratados de no proliferación de armas nucleares determinó que Washington a trabara la provisión de equipamiento militar a las FF.AA. argentinas. En este marco comenzó a acercarse a Europa para disminuir la dependencia con los EE.UU. en esta materia. El Estado Mayor Argentino diseñó el Plan Europa destinado a desarrollar una industria de armamento nacional sobre la base de patentes suministradas por los europeos (Cisneros y Escudé, 2000; Rapoport, 2005).

57 En 1967, la dictadura brasileña había propuesto a la Argentina conformar una unión aduanera que abarcara, separadamente, los sectores siderúrgico, petroquímico y agrícola. Sin embargo, la iniciativa no pudo concretarse porque para ambas dictaduras la siderurgia constituía un proyecto prioritario por su estrecha relación con la industria armamentista. Además, en los últimos años se había generado una dependencia de la Argentina con el Brasil en dicho sector, por lo que toda unión aduanera implicaría profundizar esta subordinación. El uso de los recursos hídricos de la Cuenca de la Plata constituyó otro tema conflictivo entre ambas dictaduras, al concebirlo como otro espacio de disputa desde la concepción geoestratégica (Rapoport, 2005, p. 525).

58 La reunión entre Onganía y Frei logra 'total coincidencia y acuerdo, afirma. (10 de enero de 1970). Río Negro, p. 1.

116 Si Somos Americanos. Revista de Estudios Transfronterizos 
la dictadura argentina de conformar una fuerza anticomunista regional, sino también, y fundamentalmente, la posibilidad cada vez más cierta de que triunfara en Chile un candidato a presidente que se asumía públicamente como marxista (Azcoitia, 2017).

Finalmente, en las elecciones presidenciales de 1970 triunfó el socialista Salvador Allende (1970-1973), dando comienzo a una experiencia "insólita", como la calificara Fidel Castro, tendiente a generar condiciones para la transformación radical del orden social y económico a través de la legalidad establecida por la "democracia burguesa". Este escenario inédito hacía suponer que las relaciones con la Argentina volverían a tensarse habida cuenta el antimarxismo declamado por la dictadura de ese país. Sin embargo, lejos de detenerse, el acercamiento a Chile se profundizó con la llegada del general Agustín Alejandro Lanusse (1971-1972) y el consecuente reemplazo de las "fronteras ideológicas" por el "pluralismo ideológico", en tanto visión rectora de la política exterior. Este cambio no solo tenía como objetivo abrir mercados en la región, sino también equilibrar la capacidad de negociación de la Argentina frente a la política expansiva desarrollada por el Brasil (Rapoport, 2005; Zapata y Zurita, 2005).

En este marco, las noticias sobre la declaración final de la entrevista en la ciudad de Salta, entre Salvador Allende y Agustín Lanusse, volvían a destacar la importancia de la integración física, económica y científica, al igual que el compromiso de fortalecer los vínculos de amistad entre ambos pueblos, basados en la "histórica" resolución pacífica y jurídica de las diferencias y en el respeto al "pluralismo político" ${ }^{59}$. Este último aspecto adquiría gran relevancia en momentos en que Chile parecía transitar su particular camino hacia el socialismo. La declaración manifestaba también la necesidad de incrementar los intercambios comerciales entre ambos países, predominando especialmente el rol preponderante que el sector industrial debía alcanzar en los mismos. El diario calificó el encuentro de "histórico", destacando tanto el "clima festivo" que se había vivido en la ciudad norteña, como la excelente relación personal entre los mandatarios. Esta última se desprendía de la gestualidad desplegada por ambos, de la cual el Río Negro, una vez más, se constituyó como un propalador acrítico ${ }^{60}$. Para el diario, esta entrevista significó un quiebre en las relaciones binacionales al "desterrar" definitivamente la "línea políticomilitar" que pretendía conformar junto con el Brasil un "bloque atlántico de derecha" que confrontara con el "giro izquierdistas" que estaba produciéndose en el Pacífico ${ }^{61}$. Los argumentos del diario en favor de este cambio abordaron el tema desde una dimensión socioeconómica. En este sentido, sostenía que era conveniente para la Argentina iniciar

59 Finalizó la entrevista entre Lanusse y Allende. (25 de julio de 1971). Río Negro.

60 Lanusse y Allende en Salta. (24 de julio de 1971). Río Negro.

${ }_{61}$ Repercusiones de la entrevista. (25 de julio de 1971). Río Negro. 
un proceso de integración con el bloque andino, ya que el mismo se componía de países con una estructura económica diferente a la brasileña. El artículo establecía una clara distinción entre el modelo industrial exportador, sostenido por esta última, el cual requería de una política exterior agresiva, y el impulsado por los "regímenes sociales modernos" del Pacífico, tendientes a alcanzar un desarrollo basado en el mercado interno que a su vez permitiera integrar a su población. A pesar de este apoyo en materia de política exterior, el diario rionegrino fue crítico de la dictadura de Lanusse por considerarla un proceso político agotado que debía dar paso a la disputa democrática como forma de resolver los profundos conflictos por los que atravesaba la Argentina (Azcoitia, 2017).

De esta manera, al igual que durante los gobiernos de Frondizi, Illia y Onganía, el diario volvía a establecer que las "estériles" disputas fronterizas con Chile debían subsumirse a imperativos de trascendencia histórica, como la conformación de este bloque regional ${ }^{62}$.

La reunión de Antofagasta, realizada en el contexto de una gira del general Lanusse por Chile y Perú, incorporó a la agenda bilateral la firma de un convenio laboral que comprendía a los trabajadores chilenos en la Argentina, tema que el Río Negro destacó en su primera plana como uno de los principales logros del encuentro ${ }^{63}$. Esto no resulta extraño ya que, como hemos visto, para la clase dominante norpatagónica, de la cual formaba parte la familia propietaria del Río Negro, la fuerza de trabajo trasandina constituía un eslabón fundamental para la sustentabilidad de su actividad principal: la fruticultura.

En el escenario informativo patagónico, el acercamiento a Chile profundizaba sus aspectos económicos reinstalando los proyectos de integración física y comercial. En este marco debemos interpretar el editorial del diario destacando las "brillantes posibilidades" que brindaría para el comercio y la explotación del "circuito turístico internacional", la construcción de rutas en la franja cordillerana, luego de que Vialidad Nacional declarara como prioritarios los pasos internacionales de las provincias de Río Negro y Neuquén. Según el Río Negro, la concreción de estas obras constituiría un avance concreto en función de lo acordado en la entrevista de Salta ${ }^{64}$. Esta perspectiva se reforzaba con la noticia de que el Consejo de Planificación y Acción para el Desarrollo analizaba la posibilidad de incrementar los intercambios comerciales de la zona del Alto Valle y Neuquén con el mercado chileno y países del Pacífico. Sin embargo, las manifestaciones sobre la profundización de los vínculos binacionales no se agotaron en la esfera económica. Las

\footnotetext{
Semana política. (29 de julio de 1971). Río Negro.

3 El presidente Lanusse finalizó la gira. (18 de octubre de 1971). Río Negro, p. 1.

64 Comercio y turismo con Chile. (5 de septiembre de 1971). Río Negro.
} 
crónicas sobre los festejos de la independencia trasandina, que el diario publicaba año a año visibilizando la presencia y arraigo de la comunidad chilena en la zona, daban cuenta también de la dimensión simbólica de este acercamiento al referir en esta ocasión a la "emotiva ceremonia" celebrada en una escuela neuquina con motivo de su bautismo con el nombre de "República de Chile"65. Como hemos observado hasta aquí, las noticias sobre los estrechos vínculos binacionales en el espacio patagónico constituyeron una constante en la superficie redaccional del diario rionegrino. Sin embargo, el rasgo novedoso con relación al período anterior fue la centralidad que volvía a asumir el Estado como articulador de dichas relaciones.

En síntesis, la asunción de Lanusse pareció consolidar el cambio en materia de política exterior que comenzó a vislumbrarse hacia fines del onganiato. En este contexto, las frecuentes noticias sobre tensiones con Chile, que en ocasiones respondían a la tesis de las "fronteras ideológicas" y en otras al ancestral temor del nacionalismo territorial, dieron paso a los discursos intergracionistas impulsados por la nueva orientación de la cancillería argentina. A pesar de ello, los conflictos suscitados tras la fuga de Rawson ${ }^{66}$ evidenciarían la imposibilidad de soslayar las profundas diferencias políticas que existían entre ambos gobiernos, como pretendía el "pluralismo ideológico" promovido por el dictador Lanusse.

Con el retorno de la democracia en la Argentina y el triunfo del candidato peronista Héctor J. Cámpora, las noticias publicadas en el Río Negro no solo recobraron el tono cordial que había predominado en los encuentros de Salta y Antofagasta, sino también revelaron un cambio cualitativo en los discursos en torno a la integración, los cuales adquirieron una mayor densidad político-ideológica de la que habían dado cuenta hasta ese momento. Durante la asunción de Cámpora, circuló profusamente por el diario rionegrino un potente discurso antiimperialista que bogaba por la unidad latinoamericana. En esta línea se inscribían las palabras de Salvador Allende, presente en dicha asunción, celebrando el "reencuentro de la Argentina con un gobierno popular", a la vez que destacaba la trascendencia de un cambio que permitiría a la región marchar "unida hacia su liberación" ${ }^{7}$. El presidente chileno evocaba el "mandato de los próceres" para

65 Aniversario de Chile (19 de septiembre de 1971). Río Negro.

${ }_{66}$ El 15 de agosto de 1972, veinticinco presos políticos se fugaron del penal argentino de Rawson, seis de los cuales lograron huir hacia Chile en un avión secuestrado por compañeros que se encontraban en libertad, mientras que los restantes debieron tomar el aeropuerto para negociar su rendición. Este hecho no solo golpeó la imagen pública de la dictadura, sino también las relaciones de esta con el gobierno socialista de Allende, quien otorgó un salvoconducto a los fugados para que prosiguieran su viaje hacia Cuba, desconociendo el pedido de extradición de la dictadura argentina.

67 Actividades de delegaciones del extranjero (25 de mayo de 1973). Río Negro. 
afirmar que debía lucharse por una América "integrada, independiente y soberana”68. En su discurso, Héctor Cámpora asumía como propias estas demandas, comprometiéndose a impulsar la "cooperación estrecha con los países del Tercer Mundo y especialmente con los de América Latina”. El mandatario argentino cuestionaba también el rol de la Organización de Estados Americanos, afirmando que era una institución que no servía "a los fines de la liberaciones" de los pueblos de la región ${ }^{69}$. Durante la efímera convivencia entre estos presidentes pareció cristalizarse en el diario un discurso que articulaba frontera, migración e integración sobre la base del antiimperialismo y la equidad social. Sin embargo, el golpe de Estado en Chile de septiembre de 1973 y el avance de los sectores de derecha dentro del gobierno peronista provocaron un desplazamiento de sentido sobre la cooperación y la integración binacional que progresivamente fue adquiriendo un marcado carácter "antimarxista", el cual se acentuó a partir del derrocamiento de la presidenta Estela Martínez de Perón, en 1976.

\section{Conclusión}

El discurso polifónico desplegado por el diario Río Negro entre los años 1960 y 1973 evidenció el proceso de resignificación al que estuvo sometido el concepto de integración a lo largo de un complejo y cambiante contexto, permanentemente tensionado entre dictadura y democracia, revolución y conservadurismo, radicalidad y reformismo.

A comienzos de la década del sesenta, las noticias sobre la creación de un mercado común americano permitían percibir la creciente influencia del proyecto regional cepalino. Bajo esta perspectiva, se establecía una secuencia causal en la que la integración económica se convertía en condición necesaria para la expansión del proceso industrial, el cual a su vez debía mejorar las condiciones materiales de las masas marginadas, asegurando de esta forma la estabilidad de los sistemas políticos de la región. Desde esta perspectiva, la integración contribuiría al éxito del camino reformista, permitiendo sortear tanto la radicalidad revolucionaria como el conservadurismo dictatorial. En este marco, las páginas del Río Negro mostraron a Chile como el país a la vanguardia de este proceso, con una clase política consciente de la imperiosa necesidad de subsumir las querellas domésticas al objetivo de la integración regional. Esta concepción, sostenida y reforzada por el propio diario, apelaba al tiempo como prueba irrefutable de que la unidad

68 Allende: hay que luchar por una América soberana (29 de mayo de 1973). Río Negro.

69 Exigiré respeto y obediencia de todo el personal militar (26 de mayo de 1973). Río Negro. 
argentino-chilena constituía un imperativo histórico. En esta matriz, la referencia al pasado construía un mítico origen común en las luchas independentistas, el presente emergía signado por la integración económica y la industrialización, mientras que el futuro constituía el momento en que finalmente se plasmaría el destino de grandeza que aguardaba a ambas naciones.

Durante las presidencias Arturo Illia y Eduardo Frei, el discurso integracionista amplió su campo semántico otorgándoles mayor relevancia a las dimensiones política y cultural. En este escenario, las evocaciones a las figuras de San Martín y O’Higgins contenían el mandato de continuar la inconclusa empresa independentista. Sin embargo, el contexto también estuvo signado por la presencia del conflicto fronterizo, como se evidenció luego de la irrupción del incidente de Laguna del Desierto. Quizás este haya sido uno de los momentos en que la prensa plasmó con mayor claridad la profunda tensión que existía entre las lecturas sobre los vínculos binacionales en clave "integracionista", presentada hasta el momento como un imperativo histórico para ambas naciones; y aquellas que construían la imagen de un "Chile expansionista", acuñadas por la matriz discursiva del nacionalismo territorial. En este contexto, la línea editorial del diario rionegrino continuó sosteniendo la integración con Chile como un proyecto que debían trascender las disputas territoriales, diferenciándose de la posición asumida por los principales medios capitalinos.

Este discurso nacionalista adquirió mayor preponderancia durante los primeros años de la "Revolución Argentina", en los cuales las noticias sobre relaciones binacionales comenzaron a configurar un escenario marcado por las tensiones y la desconfianza, desplazando de la agenda periodística los temas referidos al proceso de integración. Sin embargo, a pesar del discurso nacionalista territorial de la dictadura de Onganía, del cual la línea editorial del diario no estuvo completamente ajena, a fines de los sesenta comenzó a producirse un cambio en materia de política exterior que implicó el paso de la tesis de "fronteras ideológicas" a la del "pluralismo ideológico". En este nuevo contexto, las páginas del Río Negro evidenciaron un repliegue de los temas vinculados a los diferendos limítrofes y el consecuente retorno de la integración como tema estructurante de la agenda binacional. Asimismo, es importante señalar que ambos escenarios, tanto el de la tensión y desconfianza como el de profundización de la integración, se sucedieron en el contexto de una dictadura militar en la Argentina. Esto adquiere más relevancia aún si tenemos en cuenta que a partir de 1970, Chile se encontraba gobernado por un partido que se asumía públicamente como marxista. 
Durante la breve coexistencia entre el presidente socialista chileno y Héctor J. Cámpora, la integración adquirió una densidad política inédita, inscribiéndose en una trama de sentido que articulaba el "americanismo", con las tradiciones "dependentistas", "antiimperialistas" y "tercermundistas". Sin embargo, el avance de la derecha peronista y el posterior derrocamiento del gobierno socialista chileno generaron condiciones para la resignificación de las referencias públicas sobre la integración, las cuales fueron adquiriendo un marcado carácter anticomunista.

Para finalizar, queremos destacar que durante el período analizado en nuestro artículo predominó en el Río Negro una línea editorial que estuvo a favor de los procesos de integración económicos y políticos con Chile. Consideramos que esta posición asumida por el diario respondió tanto a la defensa de intereses de la clase dominante del Alto Valle, a la cual pertenecía la familia propietaria del Río Negro, como a la propia historia de una región cuya relación con Chile es un elemento constitutivo de su identidad. También podemos inferir que la postura integracionista se vinculó con la influencia que este tipo de proyectos tuvieron a lo largo de la década del sesenta y setenta, fundamentalmente en un diario que, asumiendo el "imaginario civilizatorio", pretendía irradiar en la Norpatagonia lo que concebía como las principales ideas de su época.

\section{Bibliografía}

Ansaldi, W. (2004). Matriuskas de terror. Algunos elementos para analizar la dictadura argentina dentro de las dictaduras del Cono Sur. En A. Pucciarelli (Coord.), Empresarios, tecnócratas y militares. La trama corporativa de la última dictadura (pp. 27-51). Buenos Aires: Siglo Veintiuno.

Aronskind, R. (2003). El país del desarrollo posible. En D. James (Dir.), Nueva Historia Argentina. Tomo IX: Violencia, proscripción y autoritarismo (1955-1976) (pp. 63-114). Buenos Aires: Sudamericana.

Azcoitia, A. (2013). El diario Río Negro (General Roca) y las representaciones sobre Chile durante los primeros años de la provincia: una trama multiescalar. Pilquen, 16(2), 1-11.

Azcoitia, A. (2016). Del destino común a la invasión de... fuerzas armadas extranjeras en sólo unas horas. Chile en la prensa norpatagónica durante el incidente de Laguna del

122 Si Somos Americanos. Revista de Estudios Transfronterizos 
Desierto. En M. Nicoletti, A. Núñez y P. Núñez (Comps.), Araucanía-Norpatagonia. Discursos y representación de la materialidad (pp. 129-154). Viedma: Editorial UNRN.

Azcoitia, A. (2017). La Argentina frente al gobierno de Allende, la mirada del diario Río Negro. Estudios Fronterizos, 18(36), 102-125.

Azcoitia, A. y Núñez, P. (2013). Elementos de tensión en la planificación del desarrollo hidroeléctrico en norpatagonia (1911-1961). Revista de Historia Americana y Argentina, 48(1), 101-134.

Azcoitia, A. y Núñez, P. (2014). Las represas hidroeléctricas de la región Comahue: expectativas de un desarrollo. Agua y Territorio, 4, 12-22.

Baeza, B. y Lagos, L. (2016). Expansión urbana, religiosa católica y barrios chilenos en Comodoro Rivadavia (1950-1973). En M. Nicoletti, A. Núñez y P. Núñez (Comps.), Araucanía-Norpatagonia. Discursos y representación de la materialidad (pp. 217-242). Viedma: Editorial UNRN.

Bandieri, S. y Blanco, G. (2012). Promesas incumplidas: hidroenergía y desarrollo agrario regional en la norpatagonia argentina. Estudios Rurales, 1(2), 148-171.

Bandieri, S. y Blanco, G. (2015). Las frutas de la Patagonia. Pomáceas en el Alto Valle de Río Negro (Argentina). En P. Lacoste y J.A. Yuri (Comps.), Frutales, Cultura y Sociedad. Un recorrido histórico de la fruticultura universal, y los orígenes de la fruticultura chilena hasta nuestros días (pp. 143-167). Editorial Universidad de Talca, Chile.

Bohoslavsky, E. (2009). El complot patagónico. Nación, conspiracionismo y violencia en el sur de Argentina y Chile (siglos XIX y XX). Buenos Aires: Prometeo.

Borrat, H. (1989). El periódico, actor político. Barcelona: Gustavo Gili.

Carassai, S. (2013). Los años setenta de la gente común. Buenos Aires: Siglo XXI.

Cavaleri, P. (2004). La restauración del Virreinato. Orígenes del nacionalismo territorial argentino. Buenos Aires: Universidad Nacional de Quilmes.

Cavarozzi, M. (2009). Autoritarismo y democracia (1955-2006). Buenos Aires: Ariel. 
Cisneros, A. y Escudé, C. (2000). Historia general de las Relaciones Exteriores de la República Argentina (1806-1989). Recuperado de http://www.argentina-rree.com

Devés, E. (2003). El pensamiento latinoamericano: desde la CEPAL al neoliberalismo 19501990. Buenos Aires: Biblos.

Diario Río Negro, General Roca, 1960-1973.

Diario Clarín, Ciudad Autónoma de Buenos Aires, 1960-1973.

Diario La Nación, Ciudad Autónoma de Buenos Aires, 1960-1973.

Fairclough, N. (1992). Discourse and social change. London: Routledge.

Fermandois, J. y Hulaud, M.L. (2005). ¿Antinomia entre democracia y gobierno militar? Chile y Argentina en el momento de incertidumbre (1955-1973). En P. Lacoste (Comp.), Argentina Chile y sus vecinos. Tomo II (pp. 93-141). Mendoza: Caviar Blue.

Hobsbawm, E. (1995). Historia del Siglo XX. Barcelona: Crítica.

Iuorno, G. (2008). La provincialización de Río Negro. Interregno y conflictos de intereses nacionales y locales. En G. Iuorno y E. Crespo (Coords.), Nuevos espacios, nuevos problemas. Los territorios nacionales (pp. 503-523). Neuquén: Educo-Universidad Nacional del Chomahue-Universidad Nacional de la Patagonia San Juan BoscoCehepyc Editores.

Lacoste, P. (1996). El paso de la cordillera de los Andes por el Portillo argentino. Aportes para el estudio de la integración entre Argentina y Chile. Revista Universum, 11, 101-122.

Lacoste, P. (1998). El sistema Pehuenche. Frontera, sociedad y caminos en los Andes Centrales argentino-chilenos (1658-1997). Mendoza: Facultad de Ciencias Políticas y Sociales y Gobierno de Mendoza.

Lacoste, P. (2003). La imagen del otro en las relaciones de la Argentina y Chile (1534-2000). Buenos Aires: Fondo de Cultura Económica.

Lacoste, P. (2013). El ferrocarril Trasandino (1872-2013). Santiago: Editorial IDEA.

Martín Rojo, L. (1997). El orden social de los discursos. Discurso, 21-22, 1-37.

124 Si Somos Americanos. Revista de Estudios Transfronterizos 
Mazzei, D. (2012). Bajo El Poder de la Caballería. Buenos Aires: Eudeba.

Medina Valverde, C. (2002). Chile y la integración latinoamericana: política exterior, acción diplomática y opinión pública, 1960-1976. Tesis Doctoral. Universidad Complutense de Madrid, Madrid.

Mires, F. (1989). La rebelión permanente. Las revoluciones sociales en América Latina. México, D.F.: Siglo XXI.

Navarro Floria, P. y Nicoletti, M.A. (2001). Río Negro. Mil voces en una historia. Neuquén: Manuscrito Libros.

Nercesian, I. (2013). La política en armas y las armas de la política: Brasil Chile y Uruguay, 1950-1970. Buenos Aires: Clacso.

Núñez, P. y Barelli, A.I. (2013). Marcas urbanas y sentidos sociales en disputa. San Carlos de Bariloche, Argentina (1966-1983). Revista Historelo, 5(10), 164-196.

O’Donnell, G. (2010). El Estado burocrático autoritario. 1966-1973: triunfos, derrotas y crisis. Buenos Aires: Prometeo.

Pelosi, H.C. y Machinandiarena de Devoto, L. (2012). Las relaciones internacionales en la presidencia de Frondizi: desarrollo, integración latinoamericana y paz mundial. Recuperado de http://bibliotecadigital.uca.edu.ar/repositorio/libros/relacionesinternacionales-presidencia-frondizi.pdf.

Pozzi, P. y Schneider, A. (2000). Los setentistas. Buenos Aires: Eudeba.

Prislei, L. (2001). Pasiones sureñas. Prensa, cultura y política en la Frontera Norpatagonia (1884-1946). Buenos Aires: Entrepasados/Prometeo Libros.

Rapoport, M. (2005). Historia económica, política y social de la Argentina (1880-2003). Buenos Aires: Ariel.

Ruffini, M. (2001). Autoridad, legitimidad y representaciones políticas. Juegos estrategias de una empresa perdurable: Río Negro y La Nueva Era (1904-1930). En L. Prislei (Dir.), Pasiones sureñas. Prensa, cultura y política en la frontera norpatagónica (1884-1946) (pp. 101-126). Buenos Aires: Entrepasados/Prometeo libros. 
Ruffini, M. (2007). La pervivencia de la República posible en los territorios nacionales. Poder y ciudadanía en Río Negro. Buenos Aires: Universidad Nacional de Quilmes.

Simonoff, A. (2007). ¿Autonomía limitada o los límites de la autonomía? El análisis de la política exterior argentina durante la gestión de Illia (1963- 1966). Tesis Doctoral. Facultad de Ciencias Jurídicas y Sociales de la Universidad Nacional de la Plata, La Plata.

Sztulwark, S. (2005). El estructuralismo latinoamericano: fundamentos y transformaciones del pensamiento económico de la periferia. Buenos Aires: Prometeo Libros.

Trpin, V. (2004). Aprendiendo a ser chileno. Identidad, trabajo y residencia de migrantes en el Alto Valle de Río Negro. Buenos Aires: Antropofagia.

Valenzuela Lafourcade, M. (1999). El enigma de la Laguna del Desierto. Una memoria diplomática. Santiago: LOM.

Zapata, V. y Zurita, M.D. (2005). Las vacilaciones de la Revolución Argentina en su Política Exterior: ¿Alineamiento norteamericano o nacionalismo heterodoxo? Relaciones Internacionales, 29, 145-151. 